\title{
A criação da marca pessoal de uma designer
}

\section{The creation of a designer's personal brand}

\author{
Kimberly Nunes Nunes Ferreira ${ }^{[1]}$, \\ Chris de Azevedo Ramil ${ }^{[2]}$
}

\begin{abstract}
Resumo: Este artigo tem como objetivo apresentar os principais aspectos do processo de criação de marca pessoal para uma designer recém graduada, no caso, a autora deste trabalho. Visando a inserção no mercado de trabalho com design gráfico, é importante a concepção de uma identidade visual que seja representativa da profissional, para ser aplicada em alguns materiais. Para isso, adotou-se a referência de Bruno Munari (2008) como principal metodologia para o desenvolvimento do projeto, sendo base para a pesquisa, análises, verificações e criação da proposta final da marca. Além disso, os estudos de outros autores, tais como Alina Wheeler e Gilberto Strunck, sobre marca, identidade visual e projeto gráfico, também contribuíram para o desenvolvimento do trabalho aqui apresentado.
\end{abstract}

Palavras-chave: Marca. Identidade Visual. Projeto Gráfico.

Abstract: This article aims to present the main aspects of the personal branding process for a newly graduated designer, in this case, the author of this work. Aiming the participation in the graphic design job market, it's important to design a visual identity that is representative of the professional, to be applied in some materials. For this, the reference of Bruno Munari (2008) was adopted as the main methodology for the project development, being the basis for research, analysis, verification and creation of the final brand proposal. In addition, studies by other authors, such as Alina Wheeler and Gilberto Strunck on branding, visual identity and graphic design, also contributed to the development of the work, here presented.

Keywords: Brand. Visual Identity. Graphic Project.

[1] Bacharel em Design Gráfico, UFPEL. nuneskfer@gmail.com

[2] Doutora em Educação, UFPEL. chrisramil@gmail.com 


\section{INTRODUÇÃO}

Vivemos constantemente em busca de nossa identidade, queremos descobrir o que nos difere dos demais. Qual é a nossa marca? O que nos torna únicos? Para reflexão inicial, uso o exemplo dos formatos mais reconhecidos como recurso para identificação e diferenciação dos indivíduos na sociedade em que vivemos: todas as pessoas são devidamente identificadas por meio de sua impressão digital, que é o desenho formado pelas elevações da pele encontrado na polpa dos dedos das mãos, único e específico em cada ser humano. Também somos identificados pelos nossos nomes e sobrenomes, porém, nesse caso, há casos em que estes se repetem em pessoas diferentes. Enfim, elementos como esses indicam que cada pessoa é única e possui características específicas que constituem a sua identidade, por meio da qual pode ser reconhecida.

Além disso, segundo Hall (2005), a identidade de uma pessoa também é formada pela interação com tudo o que está ao seu redor, para ele a identidade preenche o espaço que há entre o interno e o externo, criando desta forma dois mundos, um pessoal e um público. Entre outras possibilidades de identificar as pessoas, o que mais poderia nos diferenciar, perante os demais seres humanos? Pelo ponto de vista do design gráfico, uma marca também cumpriria essa função, através de suas características conceituais, estéticas e gráficas.

A partir dessas reflexões iniciais, começo então, a apresentar o tema do qual trato neste texto. Primeiramente, vale informar que apresento, aqui, um recorte de uma pesquisa mais ampla desenvolvida no Trabalho de Conclusão de Curso (TCC), realizado junto ao Curso de Design Gráfico, do Centro de Artes (CA) da Universidade Federal de Pelotas (UFPel), no primeiro semestre de 2019.

A necessidade da realização do TCC para conclusão do referido curso foi ao encontro do meu interesse pela temática, o que me levou a investir na proposta de criação de uma marca pessoal para caracterizar a minha atuação profissional como designer. Diante disso, verifiquei a importância de fazer 
uma reflexão sobre minha história, vivências, experiências, meus valores, princípios, aprendizados, contextos, referências e trajetória acadêmica. Esses aspectos contribuem para a formação de minha identidade e, por isso, foram considerados para o desenvolvimento de minha marca pessoal.

Como o foco principal do trabalho é marca, torna-se imprescindível discorrer sobre alguns conceitos relativos ao assunto e balizadores para a pesquisa. Então, faço o seguinte questionamento: o que é marca? Strunck (2007), ao definir marca, faz uma analogia:

Cada marca é como uma pessoa que teve sua personalidade própria cuidadosamente criada e desenvolvida. Essa personalidade é forjada através de suas ações de comunicação do seu design, de sua publicidade, de seu comportamento social (STRUNCK, 2007, p. 3).

Ao refletir sobre o que foi exposto até então, pode-se entender que uma marca não é apenas uma forma gráfica que dá nome e apresenta uma empresa, não é unicamente uma assinatura visual, mas sim um conjunto de elementos que a compõem: o padrão cromático, o alfabeto institucional, os itens de comunicação visual, a sinalização, as peças gráficas impressas e/ou digitais, a forma de ouvir/responder/atender seu público, a maneira de se colocar diante de questões da sociedade, como solucionar problemas que surgem com mercadorias, entre outros elementos.

Sendo assim, uma marca serve para identificar e registrar visualmente um determinado serviço, produto, atividade profissional, deve ser representativa de um estilo alinhado ao desejado e/ou solicitado por aquele que a for utilizar e ser visualmente atrativa, procurando atingir um determinado público-alvo e buscando alcançar os objetivos pretendidos.

Para que essas características sejam contempladas de forma mais eficiente, é importante recorrer aos serviços de criação de um profissional especializado na área. E esse especialista, será que tem a sua própria marca, que o identifique 
profissionalmente no ramo do mercado de design gráfico? É importante que esse profissional tenha sua marca pessoal bem desenvolvida, não apenas para tê-la como parte de seu portfólio, levando-se em consideração que uma das atividades que o designer gráfico mais desempenha é a criação de marcas, como também para se diferenciar em meio a tantos profissionais que também atuam nessa mesma área.

A demanda por serviços deste tipo costuma ser recorrente, pois há sempre alguém percebendo que a imagem de sua empresa precisa ser renovada ou melhor apresentada, ou ainda, que não possui, mas precisa ter uma marca. Para isso, os projetos gráficos desenvolvidos pelo profissional da área - o designer gráfico - devem considerar as necessidades e os perfis de seus clientes. Logo, há muito mais a se considerar para a construção de uma marca e também para mantê-la, do que apenas o que estiver visualmente aparente e, por isso, para este tipo de projeto ser desenvolvido de forma mais eficiente, devem ser considerados diversos fatores. Nesse sentido, Weber (2016, p. 69) também reflete sobre o cenário:

Apesar de, para leigos, uma marca parecer algo simples, na verdade ela representa a ponta do iceberg: é a fração aparente, resultante de uma intensa pesquisa que fica quase sempre imersa no mar da imaginação e reflexão do designer.

Levando esses aspectos em consideração e diante da necessidade de se realizar uma pesquisa detalhada, para dar suporte ao processo de criação e desenvolvimento de minha marca pessoal, o trabalho foi executado a partir de algumas ações, distribuídas em etapas, as quais algumas apresento com maior ênfase, na continuidade do texto. Entre os procedimentos metodológicos adotados no projeto estão: 1) Estudo de referências bibliográficas de autores que subsidiam a temática escolhida; 2) Leitura de alguns textos acadêmicos cujos temas principais tratem de marca e/ou identidade visual; 3) Definição de uma metodologia projetual de design para contemplar os objetivos propostos no trabalho (MUNARI, 
2008); e por fim, 4) Desenvolvimento efetivo da proposta do TCC: criação da marca e aplicação em algumas peças gráficas. A seguir, apresento o processo de criação da marca pessoal.

\section{PROCESSO DE CRIAÇÃO DA MARCA PESSOAL}

Para o desenvolvimento da marca pessoal, a metodologia que escolhi como base, identificando a possibilidade de ser usada para essa finalidade, foi a defendida por Bruno Munari (2008), um reconhecido artista e designer italiano, que contribuiu com o campo das artes visuais, através de seus estudos publicados. Apesar de esta opção metodológica ser predominantemente utilizada em projetos de produtos (mais voltados à indústria), como é possível visualizar em sua obra "Das coisas nascem coisas", decidi escolher seus métodos como um desafio e uma diferenciação ao aplicá-los em um projeto de criação de marca.

A metodologia de Munari (2008) possui fases bem elaboradas, 12 ao todo, sendo que ela pode ser adaptada de acordo com a necessidade do profissional que a utilizar. Identifiquei que essa metodologia apresenta etapas bem distribuídas, assim o projeto pôde ter em seu desenvolvimento argumentos de escolhas, por exemplo, e pesquisas com tempo hábil de realização. Além disso, o referido autor (ibidem, p. 10) defende que "O método de projeto é mais do que uma série de operações necessárias, dispostas em ordem lógica ditada pela experiência. Seu objetivo é o de atingir o melhor resultado com o menor esforço."

Os três pilares da metodologia de Munari (2008) são: Problema, Criatividade e Solução; um se encontra na fase inicial do projeto, o outro nomeio do projeto e o último na fase final do projeto. Para compreensão desse processo utilizado pelo autor, apresento, a seguir, um esquema, na Figura 1, na qual é possível visualizar as fases. Vale destacar que, conforme já mencionei anteriormente, pela flexibilidade do modelo original, o adaptei para meu trabalho e, por isso, aquelas fases que estão marcadas com um " $X$ " sobrescrito em vermelho ao lado 
direito das letras iniciais que identificam a referida etapa, foram excluídas no meu projeto, por entender que não seriam necessárias, considerando o formato e a finalidade deste.

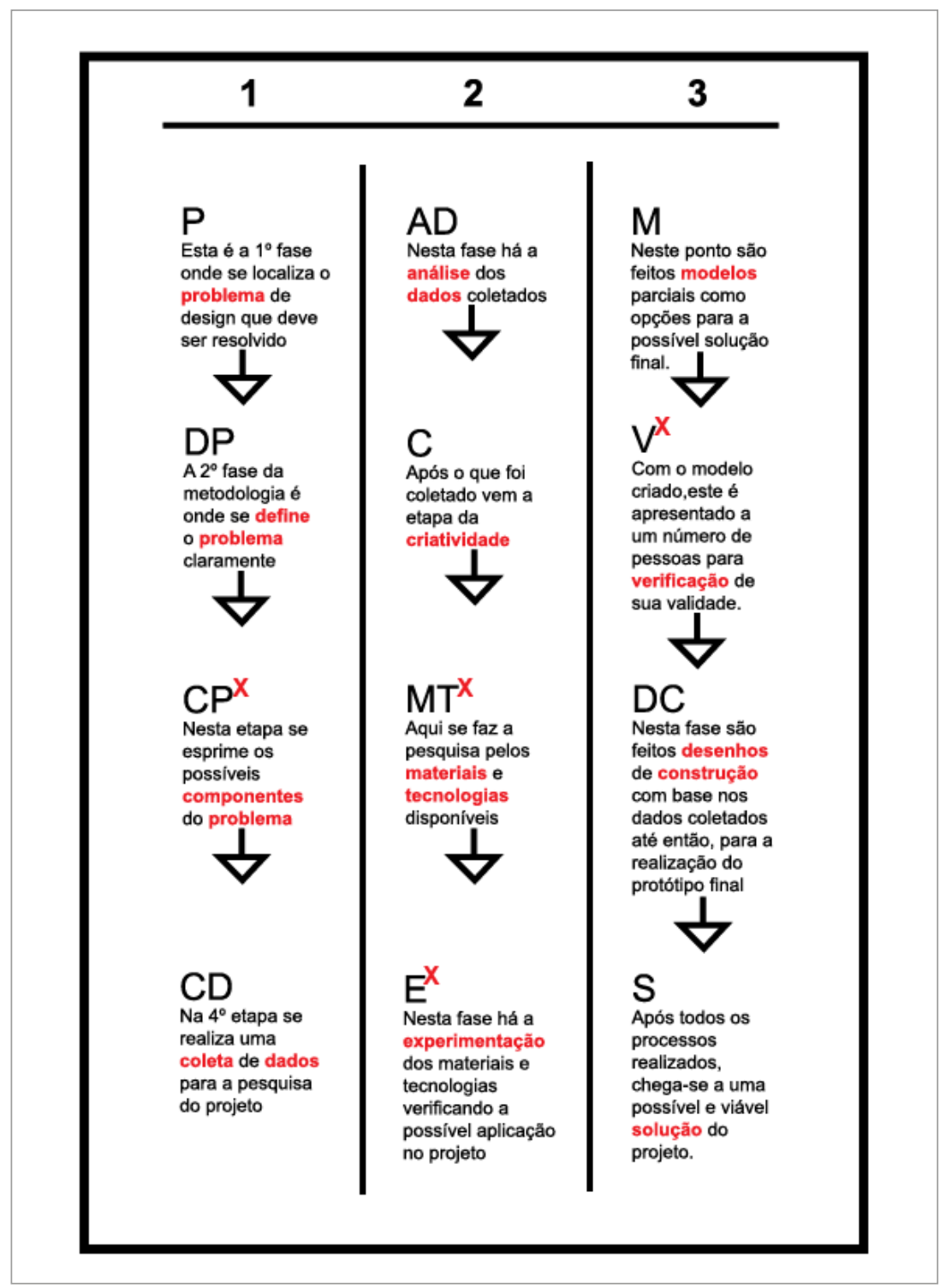

Figura 1 - Adaptação da metodologia de Munari (2008). Fonte: Munari (2008) - adaptação da autora.

A partir desse esquema, tratei de executar as devidas etapas, que podem ser conferidas, na continuidade do texto e que estão identificadas pelas fases e letras iniciais, conforme exemplificado na Figura 1, acima. No início do projeto, na 
$1^{\text {a }}$ fase da metodologia (P), identifiquei o meu "problema", que era: Como criar uma marca pessoal com base na minha pró-

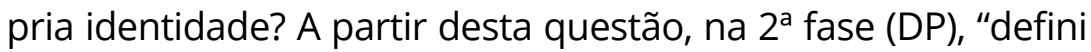
meu problema", para compreensão do que deveria estar resolvido ao final do projeto. Para isto, destaquei o problema de, ao concluir meu curso superior e estar graduada como designer gráfico, não possuir uma marca que me represente e apresente ao mercado de trabalho.

Dando continuidade ao projeto, a $3^{\text {a }}$ fase não foi executada (pelos motivos já expostos anteriormente) e, na sequência, na $4^{\text {a }}$ fase (CD), intitulada "coleta de dados", pesquisei por designers gráficos que criaram suas marcas pessoais para utilização como profissionais. A partir desse levantamento, dos 16 elencados, destaquei quatro para uma análise mais detaIhada das suas marcas, considerando os seguintes fatores: o desenho de construção e seu bom resultado visual; referência visual que se aproxima do meu senso estético; projeto gráfico com boa solução.

Outro aspecto importante para essas análises realizadas nas marcas pessoais de outros designers foi o uso de monogramas na composição do símbolo destas marcas, ou seja, os símbolos desenhados pelos designers que fazem uso das letras que iniciam seus nomes (reais e/ou fantasia), visto que seria o estilo que eu pretendia adotar na minha marca pessoal e, por isso, era importante eu observar casos com usos semelhantes. Em relação aos monogramas, segundo Wheeler (2012),eles formam um ponto focal gráfico, sendo que a letra inicial deve ter um design específico e particular, exibindo exclusividade.

Sendo assim, essas marcas destacadas fizeram parte das minhas referências visuais para o trabalho, além de serem analisadas quanto à sua estrutura. Também levei em consideração, para escolher as marcas, a formação acadêmica e o pouco tempo (na maioria, aproximadamente 2 anos) em que os respectivos designers estavam apresentando seus 
portfólios na mídia em que pretendo expor meus trabaIhos, a rede social Facebook.

Após a escolha das referidas marcas, na $5^{\text {a }}$ fase da metodologia (AD) foi feita a "análise de dados", ou seja, analisei essas marcas, desmembrando-as e verificando seus componentes. Para isto, optei por analisar as marcas presentes nos avatares das páginas de Facebook dos designers, assim como a imagem de capa que elas apresentam, além de coletar algumas informações adicionais, para melhor apresentar estes designers, em uma ficha, como é possível observar na Figura 2, a seguir, o exemplo de um dos profissionais escolhidos. $\mathrm{Na}$ imagem apresentada na Figura 3, mostro um exemplo de como realizei a análise das marcas, com o caso do mesmo designer indicado na Figura 2.

\section{VITOR LINHARES DESIGN}

Nome da página: Vitor Linhares Design

Página criada em: 10 jul. 2015

Proprietário: Vitor Linhares

Local: Suzano - SP

Curtidas/Seguidores: 6.029/6.091

Foco definido pelo designer: Desenvolvimento de marcas com design estratégico
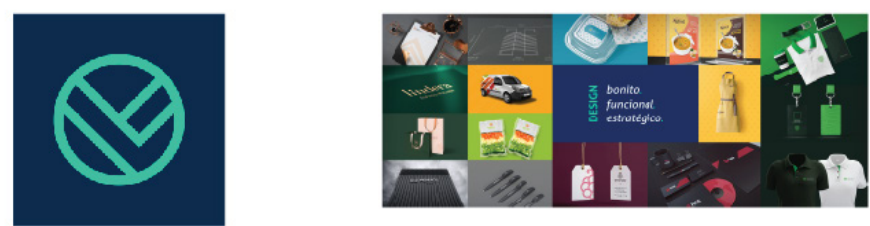

Monograma formado pela síntese de:

$\mathrm{V}+\mathrm{L}=$ Vitor Linhares;

Estrutura de formação:

4 linhas e 1 círculo

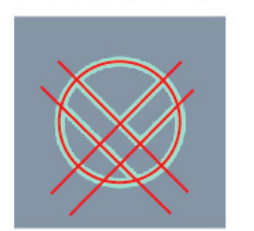

\section{- Imagens do portfólio do designer}

Um box ao centro com: a palavra Design na cor do monograma do avatar e; palavras-chave em cor branca como ponto de leveza, em meio às imagens coloridas ao redor do quadro

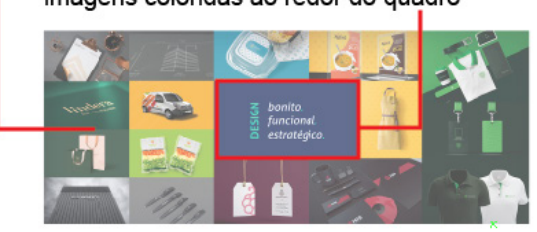

Figura 2 - Ficha de informações do designer. Fonte: da autora.

Figura 3 - Análise de marca pessoal de designer, com indicação de elementos. Fonte: da autora. 
Conforme visto no exemplo acima, primeiramente analisei a estrutura de formação de cada monograma (os símbolos presentes nas marcas de cada designer), na qual foi verificado: as linhas de formação do desenho, as cores empregadas, se havia uma tipografia reconhecível, se as letras que formavam o monograma estavam claras, como este monograma foi contido, se havia uma forma geométrica ao seu redor, se havia algum problema na marca. Após isso, analisei as capas (cabeçalhos das páginas no Facebook) para verificar os elementos gráficos que os designers faziam uso. No caso do perfil de um dos profissionais, por exemplo, o mesmo da marca apresentada anteriormente (Figuras 2 e 3), na capa dessa página constavam imagens do próprio portfólio do designer e algumas palavras com relação direta ao design.

Com essas análises, especificamente de marcas pessoais de designers, pude ter noção de como poderia diferenciar minha marca pessoal do que comumente é feito na composição de símbolo com monograma e, também, observar possibilidades de uso de elementos gráficos para meu projeto gráfico, formando minha identidade visual. Constatei também que, uma página no Facebook, dada a quantidade de pessoas que seguem os perfis dos designers analisados, gera uma boa visualização dos trabalhos destes e pode contribuir para chamar atenção de futuros clientes.

Com a finalização dessa etapa, passei para a $6^{a}$ fase da metodologia (C) que é a de "criatividade". Nesta fase, após refletir sobre os primeiros esboços e as pesquisas feitas no decorrer do projeto até então, identifiquei os conceitos que desejava contemplar na minha marca pessoal, sendo eles "força", "equilíbrio" e "criatividade". Para encontrar esses três conceitos utilizei duas estratégias. A primeira delas foi o brainstorming, um recurso muito utilizado por equipes de design, entre outras áreas, que serve para explorar um determinado problema, ao colocar no papel as características que o envolvem. No meu caso, como o problema era a criação da minha marca pes- 
soal com base na minha própria identidade, era necessário que eu refletisse sobre aspectos que envolvem essa questão. O brainstorming foi utilizado como recurso fundamental para ajudar a revelar as particularidades que definiam a Kimberly "pessoa", a Kimberly "acadêmica" e a Kimberly "designer", como se pode ver nas imagens da Figura 4, a seguir. Então, a partir das respostas coletadas, encontrei subsídios que colaboraram no processo de criação e na caracterização da minha marca pessoal, para representar a Kimberly "profissional".
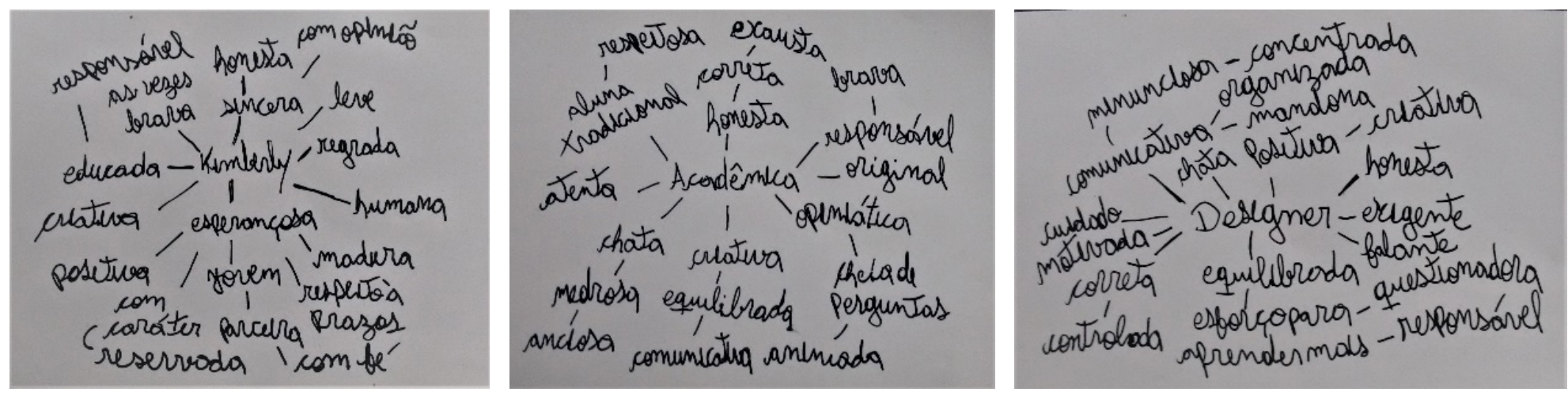

Figura 4 - Brainstorming's (da esquerda para a direita, Kimberly: "pessoal", "acadêmica" e "designer"). Fonte: da autora.

Além disso, fiz o preenchimento de um quadro de atributos conceituais (Figura 5) para definir conceitualmente meu projeto gráfico. Tais marcações também foram consideradas para a definição das características predominantes de minha marca pessoal.

\begin{tabular}{|c|c|c|c|c|}
\hline & muito & /neutro/ & muito & \\
\hline \multirow{2}{*}{$\begin{array}{l}\text { bonito } \\
\text { velho }\end{array}$} & $\mathbf{x}$ & & & feio \\
\hline & & & $\mathbf{x}$ & novo \\
\hline \multirow{4}{*}{$\begin{array}{l}\text { forte } \\
\text { alegre } \\
\text { divertido } \\
\text { passivo }\end{array}$} & $\mathbf{x}$ & & & fraco \\
\hline & $\mathbf{x}$ & & & triste \\
\hline & & $\mathbf{x}$ & & sério \\
\hline & & & $\underline{x}$ & ativo \\
\hline \multirow{5}{*}{$\begin{array}{l}\text { refinado } \\
\text { amigável } \\
\text { frio } \\
\text { vulgar } \\
\text { comum }\end{array}$} & & $\mathbf{x}$ & & bruto \\
\hline & $\mathbf{x}$ & & & hostil \\
\hline & $\bar{x}$ & & & quente \\
\hline & & & $\mathbf{x}$ & distinto \\
\hline & & & $\mathbf{x}$ & diferente \\
\hline \multirow{2}{*}{$\begin{array}{l}\text { simples } \\
\text { orgânico }\end{array}$} & $\mathbf{x}$ & & & complexo \\
\hline & & & $\mathbf{x}$ & geométrico \\
\hline
\end{tabular}

Figura 5 - Atributos conceituais para a marca pessoal. Fonte: da autora. 
No que se refere às escolhas estéticas para as aplicações de minha marca pessoal, optei por adotar características gráficas desenvolvidas pela Bauhaus. Este movimento artístico, com o qual muito me identifico, está relacionado à uma escola que pretendia unir arte e seus diversos ofícios, ensinando tanto as artes em si quanto formas de criar produtos que pudessem ser fabricados pela indústria, além de investir em novos procedimentos para se construir "coisas". Essa instituição ganhou destaque por ser considerada a primeira escola de design do século $X X$, investindo na união entre funcionalidade e estética. Ademais, Lupton \& Miller (2008, p. 8) dizem que "seu status de momento fundador do design foi reforçado pela adoção de seus métodos e ideais em escolas ao redor do mundo".

Os aspectos destacados pela Bauhaus que busquei seguir na construção do projeto foram principalmente: modernidade e minimalismo, além do uso de formas lineares e formas geométricas. As formas geométricas eram muito importantes na Bauhaus, sendo o triângulo, o quadrado e o círculo, partes da gramática central da escola (LUPTON; MILLER, 2008, p. 8). Nesse contexto, apresento na Figura 6, a seguir, um exemplo de uma marca desenvolvida por um "bauhausiano", Oskar Schlemmer, que foi professor na Bauhaus e mestre da forma na oficina de Teatro na escola, sendo considerado um artista de características cubistas.

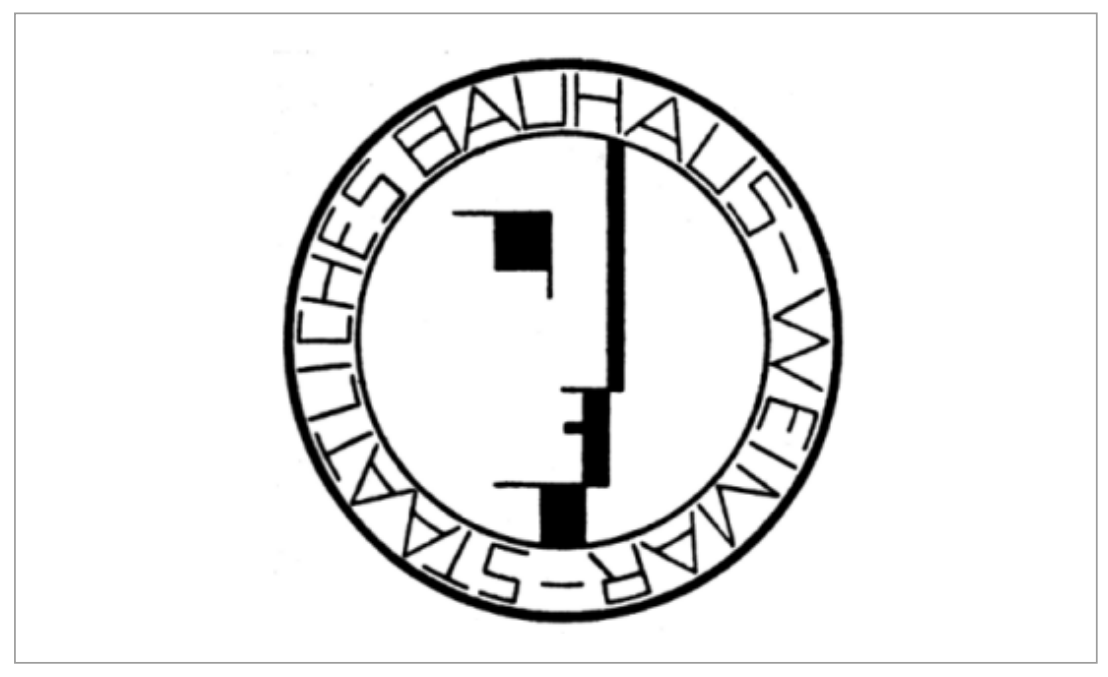

Figura 6 - Marca da Bauhaus, criada por Oskar Schlemmer. Fonte: Arteduca - Mostra Bauhaus (Disponível em: https://bit.ly/2KTey4m. Acesso em: jun. 2019). 
A partir do que foi trabalhado até este momento, fiz um Moodboard visual (Figura 7) para explicitar os três principais conceitos da minha marca pessoal, como mencionado anteriormente: força, equilíbrio e criatividade. Essas expressões formam uma síntese de todos os aspectos que foram levados em consideração para concepção da minha marca: as pesquisas, as ferramentas de geração de características (brainstorming e atributos conceituais), o estilo "bauhausiano" adotado como referência, as marcas dos designers que foram analisadas e os conceitos definidos.

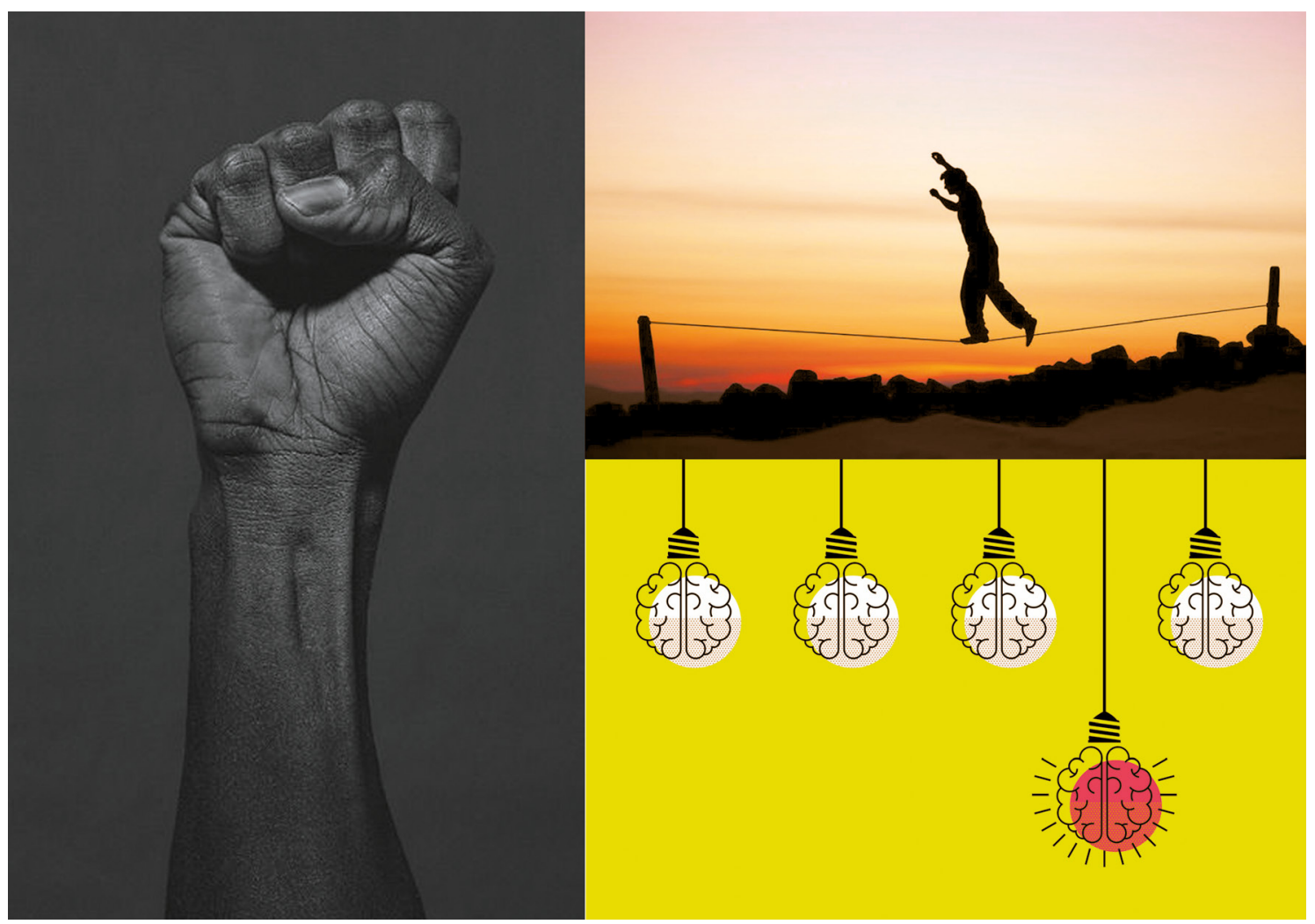

Na 9a fase da metodologia (M), nomeada "modelos", realizei diversos testes: de tipografia, onde escolhi a tipografia Montserrat para meu logotipo ("Kimberly Nunes" em caixa alta; "projetos gráficos" justapostos e em caixa baixa); de formas, no qual defini o desenho do monograma; de compo-
Figura 7 - Moodboard visual para a marca. Fonte: Perfil privado no Pinterest (Disponível em: https:// bit.ly/2XgJHkg. Acesso em: jun. 2019); Pra saber (Disponível em: https://bit.ly/2No1xBN. Acesso em: jun. 2019) e Pitaya Comunicação (Disponível em: https://bit. ly/2XG91UV. Acesso em: jun. 2019). 
sição, para verificar como ficaria a união dos elementos da minha marca. Quanto ao monograma, optei por uma solução gráfica na qual utilizei as letras " $\mathrm{K}$ " e " $\mathrm{N}$ ", iniciais de meu nome e sobrenome (Kimberly Nunes), repetidas duas vezes, rebatidas e rotacionadas, sendo que as " $K$ " se unem a partir de suas hastes em um eixo horizontal e estão nas extremidades esquerda e direita da composição, enquanto as "N" estão separadas acima e abaixo dessa estrutura unida das "K", em posição centralizada. Esses aspectos podem ser conferidos na Figura 8, apresentada na continuidade do texto.

Não realizei testes de cores, pois já havia definido as que utilizaria. Em relação a isso, mais especificamente, vale destacar a importância da escolha das cores nos projetos gráficos e, no caso de criação de marcas, elas têm muita influência, pois interferem na visualidade e expressividade e precisam estar de acordo com a imagem que a marca quer apresentar. A partir desses fatores, minha escolha de cores foi reduzida ao uso de apenas duas cores, levando em consideração a quantidade de elementos e a forma como eles interagem entre si. Essas cores são o preto e o branco, que em função da disposição das formas gráficas do símbolo, atuam conjuntamente uma com a outra, interagindo entre si, o que remete ao que costumamos chamar de "positivo/negativo", podendo o símbolo ser preto ou branco, invertendo-se a cor de fundo. Nessa relação, deve-se ter o devido cuidado, pois, assim como observam Lupton \& Phillips (2008, p. 85), o designer pode tanto construir quanto destruir formas com o uso de figura e fundo.

Optei por essas cores, em especial, porque o preto remete à seriedade e dá força às marcas, que podem chamam a atenção dentre tantas que têm alguma cor ou várias cores em sua paleta, pela potência da cor, se for bem utilizada. Admiro também marcas na cor branca em fundo preto, pois elas também denotam um tom de seriedade. Defini então, que minha marca seria sempre positiva ou negativa (em preto e branco), podendo aparecer com diferenciação de opacidade, em tons de cinza, em casos específicos de composição complementar 
para peças gráficas, como no caso dos elementos gráficos de apoio, elaborados a partir do monograma.

Dando continuidade, chegando ao fim do projeto, apresento o "desenho de construção" (DC), que constitui a $11^{\text {a }}$ fase da metodologia. Nessa etapa, trabalhei com a grade (ou grid) da marca, a partir da qual pude organizar os elementos da marca. É possível visualizar que os módulos retangulares utilizados para criar o grid, conforme destacado na Figura 8 a seguir, partiram do formato da letra "K", a qual desde o início eu queria que estivesse presente e com importância em meu projeto de marca, pela referência ao meu nome, consequentemente vinculado à minha identidade.

$\mathrm{Na}$ imagem (Figura 8) consta o grid da minha marca, no qual utilizei de largura vinte (20) módulos da letra "K" e de altura cinco (5) módulos da letra "K". A partir deles, pude organizar a proporção do logotipo e do símbolo, além de alinhar o meu nome com a minha atividade-fim. Para tais ações, utilizei o espaço de uma coluna modular entre símbolo e logotipo e uma linha modular entre os elementos do logotipo (nome e atividade-fim); para o espaçamento entre letras utilizei o pingo da letra "I" presente no logotipo.

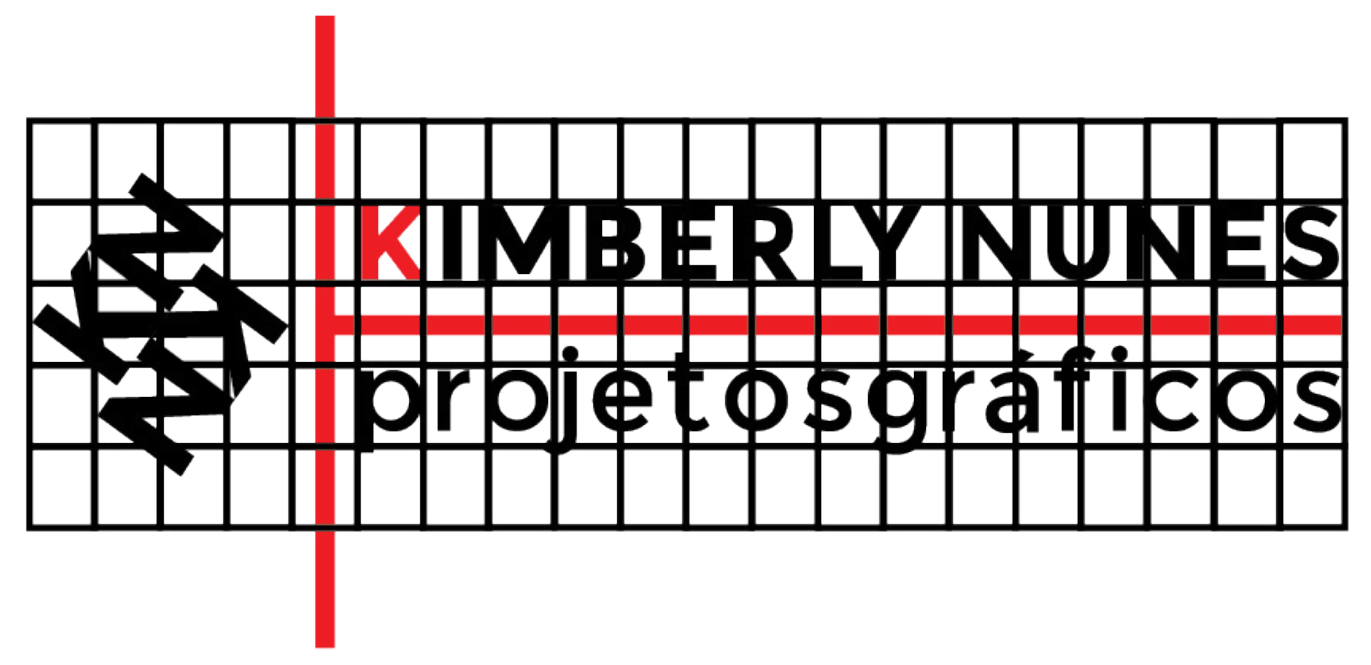

Figura 8 - Desenho de construção da marca pessoal. Fonte: da autora. 
A seguir, na Figura 9, apresento a área de proteção da marca, que serve para conter a marca e protegê-la em meio a outras marcas ou outros elementos que possam atrapaIhar sua identificação, além de também ser utilizada como espaço de respiro para os itens inseridos em um mesmo espaço. Essa área estabelecida é equivalente ao espaço ocupado pela composição da altura da letra "K" nas áreas superior e inferior e à de sua largura no que se refere às áreas esquerda e direita da marca.

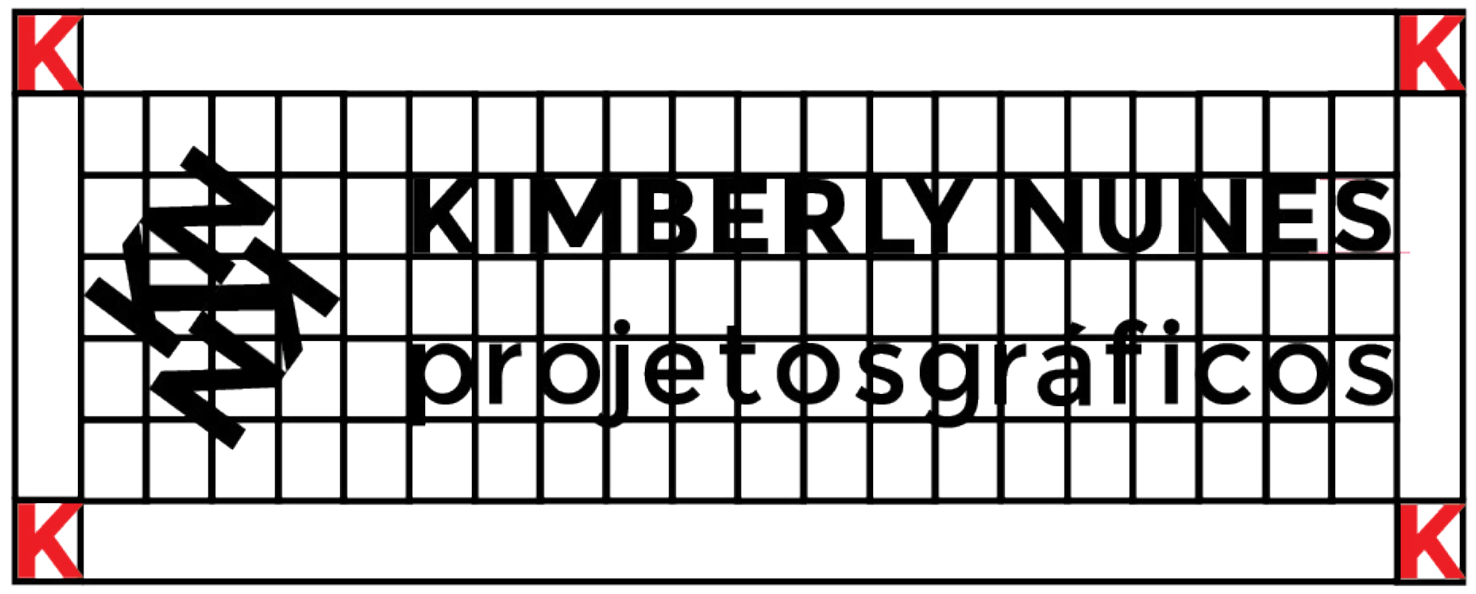

Figura 9 - Área de proteção da marca pessoal. Fonte: da autora.

Enfim, apresento a $12^{\mathrm{a}}$ e última fase $(\mathrm{S})$ dos procedimentos metodológicos, na qual trato de exibir a efetiva "solução" encontrada para minha marca pessoal. Com a proposta finalizada, nota-se a assinatura visual de minha marca, formada pelo símbolo (constituído por um monograma) e o logotipo, conforme mostra a Figura 10, a seguir. Porém, em casos específicos, em que se necessite usar a marca de forma reduzida, pode-se aplicar apenas o símbolo como opção de assinatura. 


\section{KIMBERLY NUNES projetosgráficos}

Figura 10 - Assinatura visual da marca. Fonte: da autora.

Com isso, cheguei ao objetivo pretendido, que era efetivamente ter a minha marca pessoal para uso como profissional da área de design gráfico. Concluindo este artigo apresento, a seguir, aplicações da marca em algumas peças gráficas que pretendo utilizar, tais como: cartão de visita (Figura 11), papel timbrado (Figura 12), projeto gráfico para rede social Facebook - avatar e capa (Figura 13) e também uma proposta para a composição de minhas postagens na rede social (Figura 14). Nessas aplicações é possível visualizar como explorei a utilização de uma padronagem criada a partir do monograma e de como utilizei os elementos da marca de diferentes formas.

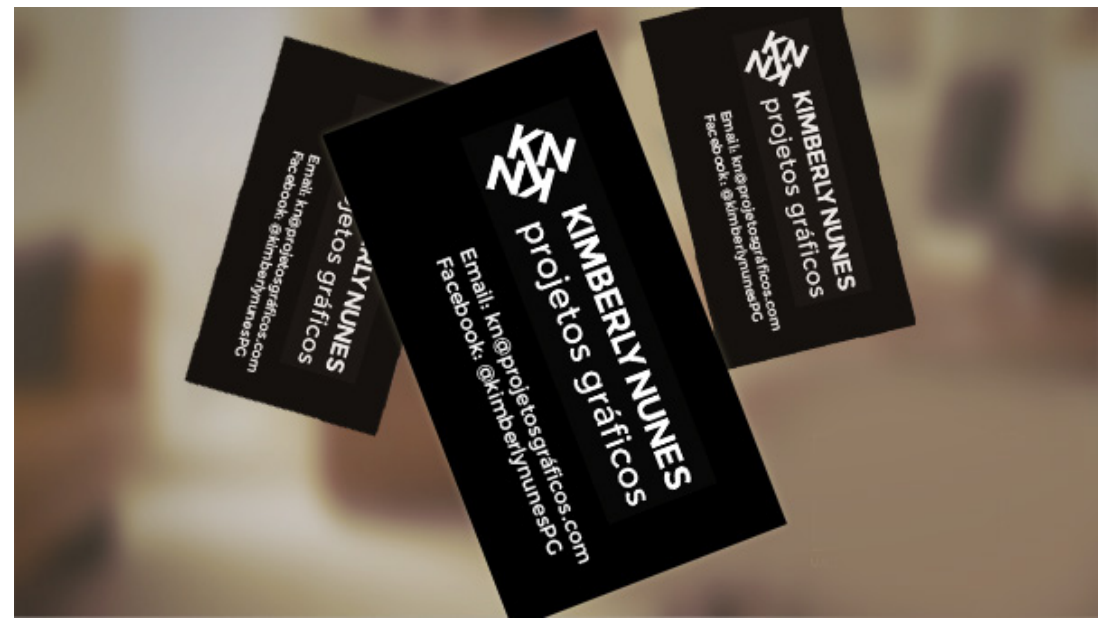


Figura 12 - Papel timbrado. Fonte: da autora.

Figura 13 - Projeto gráfico para rede social Facebook: avatar e capa. Fonte: da autora.

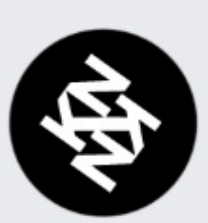

Kimberly Nunes Design gráfico (@designgráficolkn

| Pagina inicial

Fotos

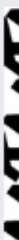

जा

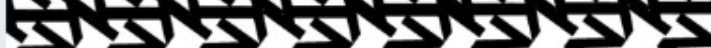

IX)

KYY KIMBERLYNUNES

projetos gráficos

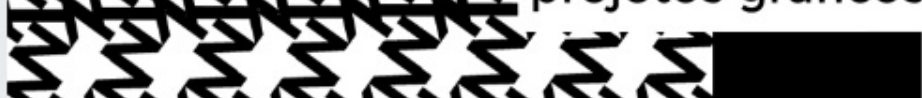

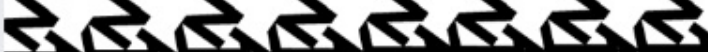

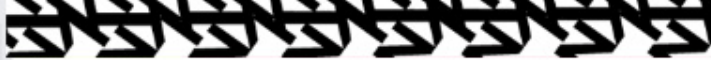

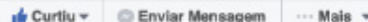

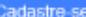

Curtidas 


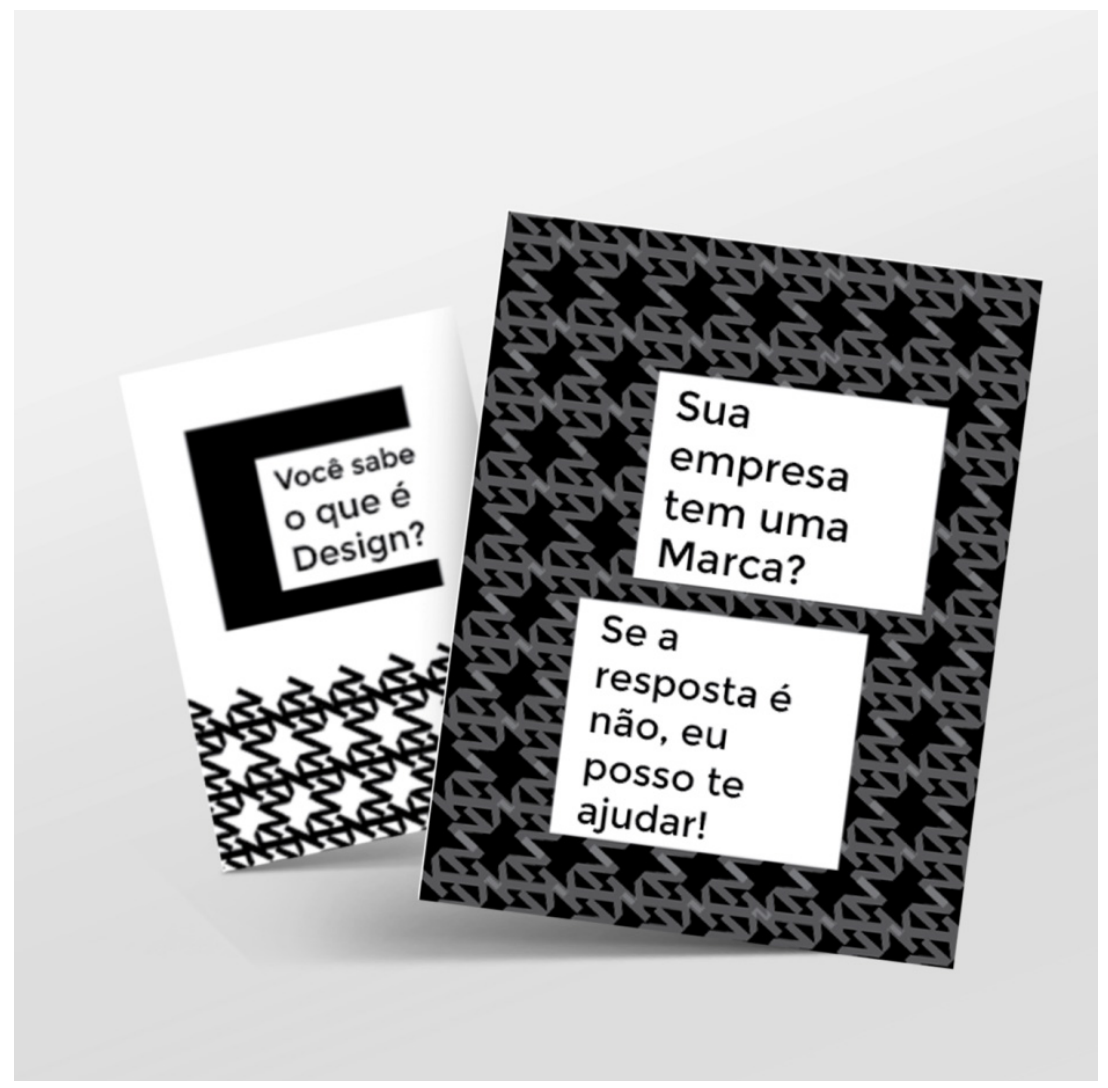

Figura 14 - Projeto gráfico para rede social Facebook: postagens. Fonte: da autora.

Com os exemplos mostrados acima é possível visualizar, enfim, os principais resultados obtidos a partir do processo de criação de minha marca pessoal, levando-se em consideração todos os referenciais teóricos, as etapas executadas anteriormente e a pesquisa detalhada que se fez necessária para contemplar os objetivos pretendidos com o projeto desenvolvido no TCC. Vale frisar que neste artigo mostro o conteúdo de forma bastante resumida, mas com o cuidado de apresentar os dados mais relevantes para o conhecimento do trabalho que desenvolvi, durante um semestre letivo.

\section{CONSIDERAÇÕES FINAIS}

Esse artigo mostra um recorte de uma pesquisa mais ampla realizada e, pelo que foi aqui mostrado, busquei explanar como se deu o processo de criação de minha marca pesso- 
al, especificamente para uso como profissional no campo do design gráfico e, para tal, apresentei os procedimentos metodológicos e as principais etapas, além de ferramentas e da discussão sobre algumas teorias que embasaram a pesquisa. Por fim, compartilhei os resultados obtidos ao final de meu trabalho, realizado como sendo requisito necessário para conclusão do curso de Design Gráfico, na UFPel.

Com a realização do TCC, cujos principais aspectos foram abordados de forma resumida neste artigo, acredito que, além de poder me beneficiar efetivamente da marca produzida e utilizar as aplicações com ela, em ambas as produções (TCC e artigo) o processo e os seus efeitos podem contribuir com acadêmicos e demais pesquisadores da área que tenham interesse em utilizar esse trabalho como referência em suas investigações, servindo de exemplo teórico-prático, também para uso real e não fictício, entre os estudos sobre a temática de marcas, em especial, as pessoais.

\section{REFERÊNCIAS BIBLIOGRÁFICAS}

ARGAN, Giulio Carlo. Walter Gropius e a

Bauhaus. Rio de Janeiro: José Olympio, 2005.

CONSOLO, Cecilia. Marcas design estratégico:

do símbolo à gestão da identidade corporativa.

São Paulo: Editora Blucher, 2015.

GOMES FILHO, João. Gestalt do objeto: sistema de leitura visual da forma. 8. ed. São Paulo: Escrituras Editora, 2008.

HALL, Stuart. A identidade cultural na pós-

modernidade. 10 ed. Rio de Janeiro: DP\&A; 2005.

KANDINSKY, Wassily. Curso da Bauhaus.

São Paulo: Martins Fontes, 1996.

LEITE, Fernando Guimarães. Projeto de identidade visual para marca de alimento produzido por 
projeto social. Porto Alegre: UniRitter, 2013. Trabalho de Conclusão de Curso (Faculdade de Design Gráfico)

- Laureate International Universities, 2013.

LUPTON, Ellen; MILLER, J. Abbott (Org.). ABC da Bauhaus: a

Bauhaus e a teoria do design. São Paulo: Cosac Naify, 2008.

LUPTON, Ellen; PHILLIPS, Jennifer Cole. Novos

fundamentos do Design. Tradução: Cristian

Borges. São Paulo: Cosac Naify, 2008.

MARTINS, Fernanda. Abc do design: Ruben Martins, um pioneiro. 2009. Disponível em: http://www.abcdesign.com. br/ruben-martins-um-pioneiro/. Acesso em: 25 jun. 2019.

MUNARI, Bruno. Das coisas nascem coisas. Tradução: José Manuel de Vasconcelos. São Paulo: Martins Fontes, 2008.

PEÓN, Maria Luísa. Sistemas de identidade

visual. 3. ed. Rio de Janeiro: 2AB, 2003.

PEÓN, Maria Luísa. Sistemas de identidade

visual. 4. ed. Rio de Janeiro: 2AB, 2009.

RIBEIRO, Milton. Planejamento visual

gráfico. 10. ed. Brasília: LGE Editora, 2007.

RODRIGUES, Delano. Naming: o nome da

marca. Rio de Janeiro: 2AB, 2011.

STRUNK, Gilberto. Como criar identidades visuais para

marcas de sucesso. 2. ed. Rio de Janeiro: Rio Books, 2007.

WEBER, Paula. Livro das Inquietações: experiências

singulares no ensino do design. Pelotas: UFPel,

2016. Dissertação (Mestrado em Artes Visuais) -

Programa de Pós-graduação em Artes, Centro de

Artes, Universidade Federal de Pelotas, 2016. 
WHEELER, Alina. Design de identidade da

marca: guia essencial para toda equipe de

gestão de marcas. Tradução: Francisco Araújo da

Costa. 3. ed. Porto Alegre: Bookman, 2012.

XIMENDES, William Barboza. Desenvolvimento de identidade de marca para uma microempreendedora

individual do ramo alimentício. Pelotas: UFPel, 2018.

Trabalho de Conclusão de Curso (Bacharelado em Design

Gráfico) - Universidade Federal de Pelotas, 2018. 